\title{
THE DEATH-MASKS OF DEAN SWIFT
}

\author{
by \\ T. G. WILSON
}

THE practice of making death-masks is of considerable antiquity, dating at least from the fifteenth century. Originally it had two purposes. One was to form the head of an effigy used in the funeral ceremonies of kings, queens, princes and other distinguished persons. A life-sized wooden effigy was made which was clothed and carried on the coffin in the funeral procession, the head and hands being covered with life-like wax modelling. This was used as a substitute for the body at funeral ceremonies which might take place long after the latter had been buried. Many of these effigies are still to be seen in Westminster Abbey. Two copies of the death-mask of Oliver Cromwell are extant, one in wax and one in plaster of paris. He died on 3 September 1658 , and his remains were quietly buried three weeks later. Nevertheless a wax effigy in full panoply of state was exhibited for several months afterwards in Somerset House while the state funeral did not take place until 22 October. John Evelyn tells us:

He was carried from Somerset House in a velvet bed of state, drawn by six horses, housed in the same; the pall held by his new Lords; Oliver lying in effigy, in royal robes, and crowned with a crown, sceptre, and globe, like a king. The pendants and guidons were carried by the officers of the army; the Imperial banners, achievements, \&c. by the heralds in their coats; a rich caparisoned horse, embroidered all over with gold; a knight of honour, armed cap-a-pie. and, after all, his guards, soldiers, and innumerable mourners. In this equipage, they proceeded to Westminster: but it was the joyfullest funeral I ever saw for there were none that cried but dogs, which the soldiers hooted away with a barbarous noise, drinking and taking tobacco in the streets as they went.

In France similar ceremonies took place. It is recorded that on the death of Charles VI of France, Maitre Francois d'Orleans, the Court painter, made a death-mask and models of the hands and feet of his late master 'for the purpose of a magnificent image'. On 3I March 1547, the day on which Francis I died, his famous Court painter Francois Clouet was hastily summoned to make a drawing of the king, to take casts of his face, hands and feet, and to prepare his effigy.

The second purpose, which holds good to this day, is to record the features of the deceased person in order to facilitate the sculptor in making a portrait bust or statue, and it was presumably for this reason the death-masks of Swift were taken. The French sculptor Roubillac (or Roubilliac) made a plaster death-mask of Isaac Newton from which he modelled a marble head, a terracotta bust now in the British Museum, and the head of a marble statue which is in Trinity College, Cambridge. The death-mask itself is in the possession of the Royal Society. It is of interest to note that Roubillac got a much better likeness of Newton than he did of Swift when he made the busts now in St. Patrick's Cathedral, Dublin, and in the Library of Trinity College, Dublin, which suggests that he did not have access to the death-masks of Swift described below. 


\section{T. G. Wilson}

\section{How Death-Masks are made}

Properly to understand the variations and vicissitudes of Swift's death-masks it is advisable to have some understanding of the way in which these masks are taken.

It is generally thought to be important to take the cast as soon after death as possible. Rubber moulds are often used today, and may be taken direct. If plaster of paris is used the hair is covered with oil or with a thin solution of modelling clay. The face is then covered with plaster of paris of a soupy consistency. Another layer of thicker plaster is then applied. When the outer layer has set hard, the mould is removed from the head to form the mould or matrix from which casts of the face are taken. This is done by filling it with plaster of paris which is allowed to set. The mould is then broken off and the mask proper is removed.

In this article the mould or matrix will be referred to as the mould, and the cast taken from it as the death-mask or cast. It is obvious that an indefinite number of copies of the death-mask can be taken from the mould, and also that a new mould may be made from any copy of the death-mask. New moulds are now usually made in gutta-percha, although I understand that as this process involves the use of considerable heat, rubber or plaster of paris is used for the first mould, that which is taken from the subject's face.

\section{The Death-Masks of Dean Swift}

Until a few years ago it was generally thought that only one death-mask of Dean Swift was in existence, this being the well-known mask in Trinity College, Dublin (Fig. I). Recently, however, two more have come to light. The first of these (Fig. 2), is quite different from the others, having been taken sooner after death, before the Dean's false teeth were removed and before the postmortem examination. This mask, which turned up quite recently, is particularly interesting because it gives us the best idea of what Swift looked like during life. It also is now in Trinity College and it is therefore described here as the second Trinity mask. The third, now in Princeton University, New Jersey (Fig. 3), is an earlier stage of the first Trinity mask, and it may perhaps be described as a modification or forerunner of it since it is obviously derived from the same original mould.

\section{The First Trinity Death-Mask}

The first Trinity mask has been known for many years. Sir Walter Scott said: in the Museum of Trinity College, Dublin, there is a dark plaster bust, or cast, of Dean Swift. It is an impression taken from the mask applied to the face after death.

Monck Mason and Sir William Wilde (then Dr. Wilde), are amongst the many others who have examined this mask, and Wilde (1849) described it minutely. He wrote:

After the Dean's death, and subsequently to the post-mortem examination a plaster mask was taken from his face, and from this a bust was made, which is now in the Museum of the University, and which, notwithstanding its possessing much of the cadaverous appearance, is, 

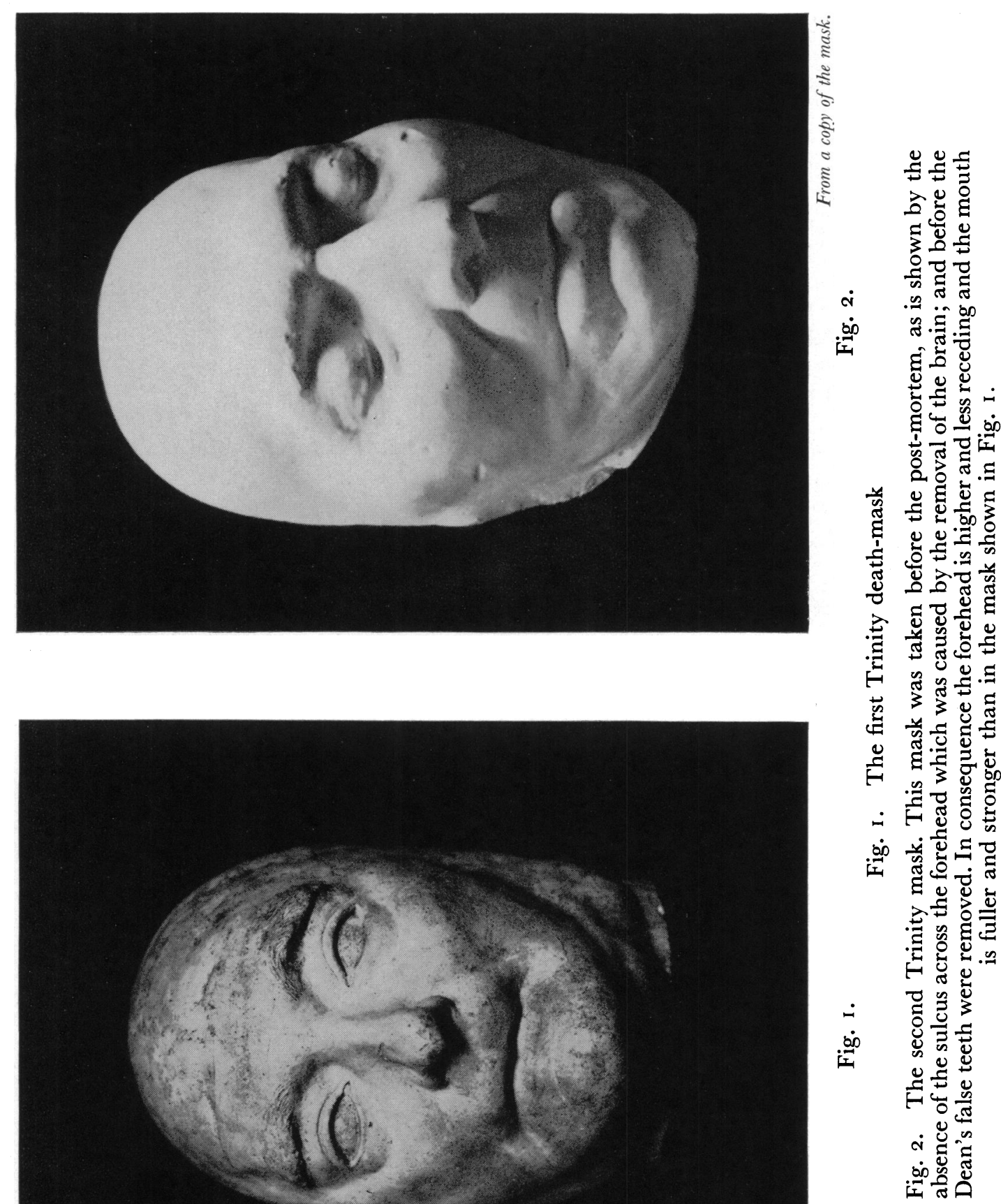


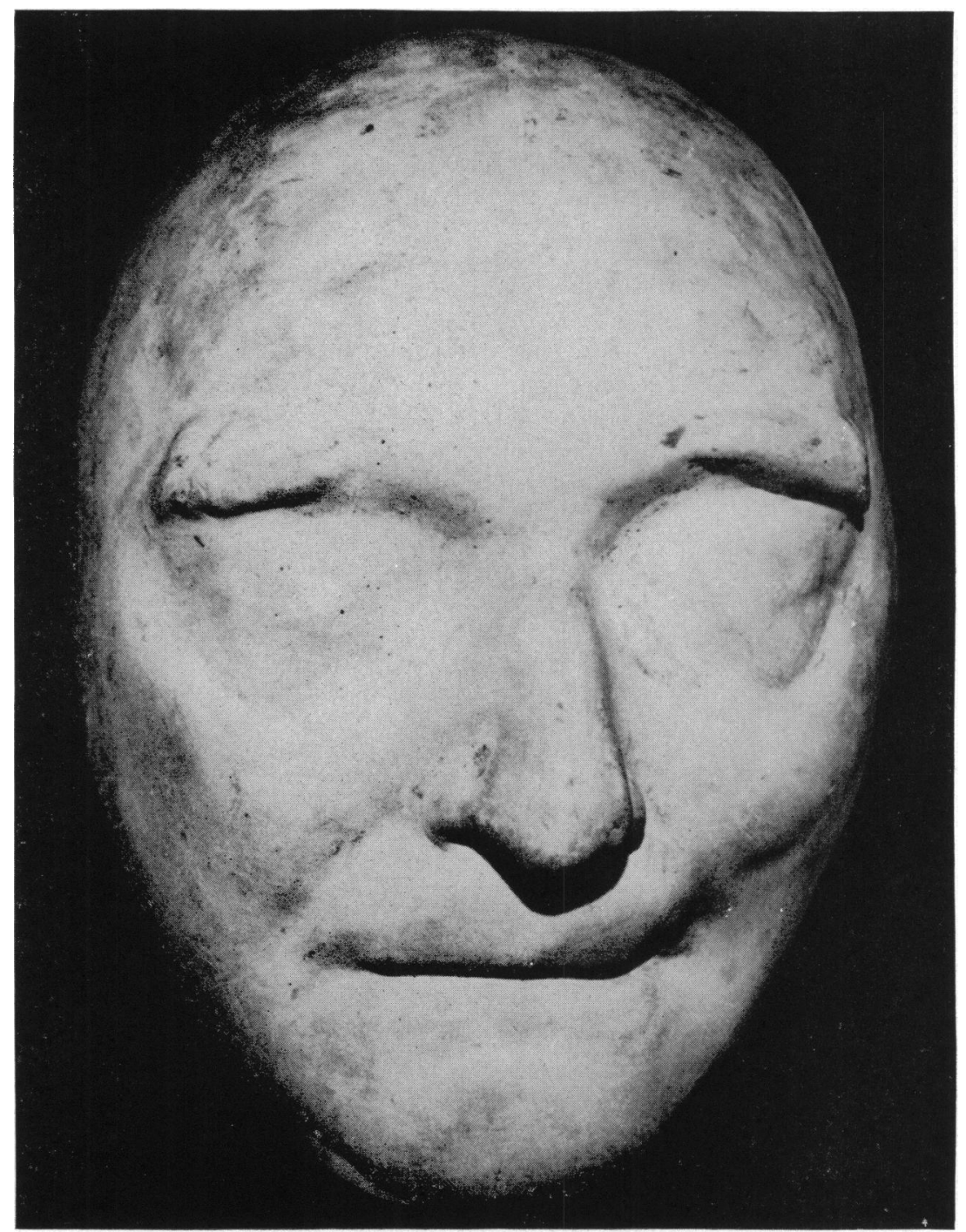

Photograph by Willard Starkes

Fig. 3 .

The Princeton death-mask. Extra plaster of paris has becn added to the eyebrows and around the eyes in preparation for carving the open eyes seen in Fig. I. 


\section{The Death-Masks of Dean Swift}

we are strongly inclined to believe, the best likeness of Swift, during, at least the last few years of his life-now in existence.

Wilde goes on to say:

This old bust, which has remained in the Museum of Trinity College from a period beyond the memory of living man, has been generally believed to be the bust of Swift; but as there is no positive proof of its being so, it has been passed over by all his biographers, except Scott and Monck Mason. ... .

\section{Wilde then attempts to identify the cast in two ways.}

Upon the back of this cast [he says], and running nearly from ear to ear, we find two (sic) lines of writing, greatly defaced, and a part of the upper and middle lines completely obliterated. This much ... [ [he continues], can still be read:

Dean Swift, taken off his - - - the night of his burial, and the f - - one side larger

than the other in nature - - Opened before - - The mould is in pieces.

Still the proof was inconclusive [he says], but a deep indentation, running nearly parallel with the brow, shows us where the calvarium had been sawn ... and this indentation accurately corresponds with the division of the skull found in Swift's coffin in 1835, thus proving incontestably the identity of both. ...

This refers to the exhumation of Swift's and Stella's remains in 1835 , when the repeated floodings of the underground River Poddle had rendered it necessary to carry out extensive repairs to the floor of the Cathedral, in the course of which their coffins were exposed.* The skeletons identified as those

* Here, with permission of the Governors of St. Patrick's Hospital, I quote what is described in The Legacy of Swift (Widdess, 1948), as a 'Typescript copy of the account by the sexton of St. Patrick's Cathedral of the opening of the graves of Swift and Stella in 1835 .' 'The original, signed by William Maguire, Sexton, August 13th, 1882, was found in a bottle in Swift's grave on September 1st, 1882, by John Lambert, assistant Sexton, who himself communicated the contents of Maguire's paper October 8th, 1917. Lambert himself wished to insert a paper in 1882, but was not permitted to do so. The original seems to have been buried again.'

The 'typescript account' reads as follows:

'The following is an accurate copy of a paper handed to me by John Lambert, sexton, of St. Patrick's Cathedral, 8th October, 1917.

'John L. Robinson, Succentor. Copy from a paper found in a bottle in Dean Swift's grave, Sept. the Ist, 1882 .

'Aug. the 3 rd 1838 . (sic) 1835 .

'Doctor Swift's grave was opened This day by the British Associate who Got Permission from the Dean. The were holding there Meeting in Dublin. The Scull of Swift was in two as it now appears having been opened after his death to examine the Braine.'

(On the other side of the paper is the following additional writing):

'Stella's Scull was taken out of the adgoing Grave and is now Deposited with Swift.

'William maguire Sexton, 13 August 1835.

'In Swift Scull was found the Bottle containing the paper. It was Sealed with red wax and had the arms of the Maguire family impressed on it. It was inside Swift Scull, it been in to part. I have seen Dean Swift grav opened and the two Sculls of Swift and Stella, and the remains of what was left of Swift. The Coffin was cleaned of the Mud and water that was in it And a box Made by a carpenter who was working at the time in the Cathedral. And the two Sculls, and the remains of Swift put in the box. And from two to three feet of concrete put over it. I suppose Never to be opened any More until the Great Day.

'At the same time I did ask the Verger Mr. Cornegie to get a Nother Bottle while the Grave was opened and to write on a paper what took place at the time and put it in the Box with Swift, but he took to long to Make up his Mind and the Grave was closed it may be for ver. I would have put a bottle and Paper in with the remains of Swift. Something about what took place at the time, but he the Verger would not Consent.

$$
\begin{aligned}
& \text { 'JOFn LAMBERT. } \\
& \text { Assistant Sexton, } \\
& \text { 'I Sept. I882.' }
\end{aligned}
$$

I may add that this second exhumation was necessitated by the same reasons as the first, and that it was carried out with much more decorum. We may also hope that the assistant sexton's supposition that it will 'Never more be opened until the Great Day' may prove true. 


\section{T. G. Wilson}

of Swift and Stella were reinterred 'a week or ten days' after the exhumation, but before this was done the opportunity was taken of making plaster casts of both skulls. The cast of Swift's skull has always been supposed to be that which is at present in Trinity College, and of which there is another example, now somewhat broken, in the Royal College of Surgeons in Ireland. The craftsman who made these casts must have taken separate moulds of the skull and of the calvarium, and then added the two parts together. In doing so he repeated the error in the Trinity death-mask which was taken after the calvarium had slipped backwards through the action of gravity, and he did not allow for the loss of bone occasioned by the saw-cut, with the result that the vault of the skull seems unnaturally low. He also obliterated the join between the skull and calvarium with plaster so well that it is almost impossible to discern it.

At the time of the exhumation Wilde was a medical student of twenty, and he did not begin his investigations of Swift's medical history until 1846. It is therefore extremely unlikely that he had an opportunity of establishing the fact that the 'indentation accurately corresponds with the division of the skull found in Swift's coffin' as he claims to have done. It is more likely that he made his comparison with the cast of the skull now in Trinity College, in which as we have seen the line of division of the skull is so indistinct, particularly in the frontal area-the only place where the division shows in the death-mask-that no definite conclusion could possibly be drawn from it.

Both Wilde's 'positive proofs' that this is Swift's death-mask therefore fall to the ground. However, proof is hardly necessary for the authenticity given to it by tradition has never seriously been questioned and there is also the strong presumptive evidence of the inscription on the back.

Let us now examine this mask in more detail. As far as can be seen it is exactly as it was when examined by Monck Mason, Sir Walter Scott, and Wilde. It is a representation of the whole head and it is clearly apparent that it was made up in two parts, the features being a cast made from a mould taken from Swift's face and the back of the head added later by guesswork. As Wilde put it:

it is at once manifest that all the posterior part is fictitious, and evidently finished out, and modelled in clay, and afterwards the plaster rasped down according to the eye of the artist.

There is indeed a marked difference between the smooth and polished face and cheeks and the rough posterior portion. The left ear is missing; the right ear, however, is present, and has obviously been taken from a separate mould and inlaid later (Fig. 2).

That it was a cast from the ear of Swift the reader has only to look at Lord Orrery's portrait, or any of the busts of the Dean, to be convinced, for Swift's ear was of a very peculiar formation.

The three lines of writing mentioned by Wilde (he specifies two, but this is obviously an error) may still be seen, but now, after the lapse of another century, it is only possible to decipher an odd word here and there with the naked eye. However, when examined by ultra-violet light, which causes ink 


\section{The Death-Masks of Dean Swift}

to fluoresce, some of the wording is quite distinct, and although it is not possible to read nearly as much as Wilde claimed to it is quite easy to correct part of his rendering. Furthermore, a fourth line, unfortunately quite illegible, is to be seen immediately below and in series with the other three. Two-thirds of an inch vertically below the beginning of this line are the initials J.D. and the indications of the remainder of a signature (Fig. 3).

What can now be clearly deciphered of the legend reads as follows:

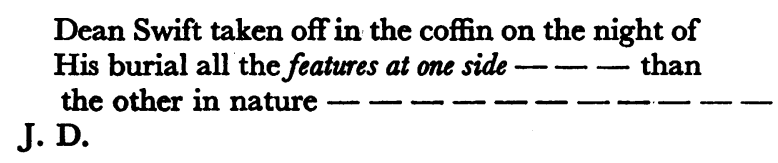

The italicised words are doubtful: e.g. 'side' should perhaps read 'wide'.

The word 'coffin' which Wilde did not decipher is quite unmistakable under the ultra-violet lamp.

Wilde's reading of the third line, which I have not been able to confirm, ends with the words 'the mould is in pieces'. In a footnote on p. 65 of his book he states 'the original mask remained in the Museum, T.C.D., till within a few years ago, when it was accidentally destroyed'. Here by 'mask' he probably meant 'mould', and if so he was again mistaken for a mould corresponding to the mask is still in Trinity, broken into seven large pieces. It is obviously of some antiquity and may well be the mould, or 'mask', to which Wilde refers. I shall return to a consideration of this mould shortly.

In this death-mask (Fig. I), the eyes are open. It may be taken as certain that as in all death-masks the eyes originally were closed, and that some unknown sculptor later fashioned open eyes as being more lifelike. No dead man's eyes were ever as open as these are, and no close scrutiny is required to ascertain that they are the work of art rather than of nature. The eyebrows are bushy and luxuriant, but they too have an artificial appearance for the hairs are too regularly parallel and the outer part of the eyebrow is square in cross-section, suggesting the super-addition of a piece of modelling clay in its formation. The mark of the saw-cut across the forehead is quite unmistakable, and to those familiar with appearances after autopsies it is also quite clear that, as is very common, the top of the skull has slipped backwards by the action of gravity after being replaced. This gives the forehead a strongly receding character. The face is obviously old and edentulous, as we would expect, for we know from the evidence of the skull-cast that Swift had lost all his teeth by the time he died. The lack of teeth gives the face a relaxed and flabby appearance, which is accentuated by the fact that the lower jaw has slipped to the left. Finally, the whole front portion has the appearance of having been smoothed down and polished.

Now let us return for a moment to the broken mould in the Trinity Museum, which as I have said is probably the mould referred to by Wilde as being lost. This mould shows the opened eyes and the added eyebrows, both of which look even more artificial in reverse than in the death-mask itself. Their presence, 


\section{T.G. Wilson}

and the lack of one ear, show that it is a mould taken from the death-mask itself for the purpose of making copies, and not from Swift's own features. It follows that this mould is of little importance. I am told that my late friend and teacher, Professor A. F. Dixon, never valued this mould as he did the other Swift relics in Trinity, and from this it may be deduced that unlike Wilde, he was aware of the fact that the death-mask had been artificially tampered with in the way I have described, and that this mould is merely an impression of the death-mask after it had been altered.

In Sir Walter Scott's description of this mask he said:

In the Museum of Trinity College, Dublin, there is a dark plaster bust, or cast, of Dean Swift. It is an impression taken from the mask applied to the face after death. The expression of countenance is most unequivocally maniacal, and one side of the mouth (the left) horribly contorted downwards, as if convulsed by pain.

This is, of course, complete nonsense. The mask shows absolutely no trace of a maniacal expression, and one must conclude that Sir Walter Scott, in describing it, was rather unworthily allowing his powers of artistic expression to get the better of him. Wilde did not agree with Scott about this, for he says:

Sir Walter has greatly exaggerated the amount of contortion which the face exhibits; on the contrary, the expression is remarkably placid, but [he goes on to say] there is an evident drag in the left side of the mouth, exhibiting a paralysis of the facial muscles of the right side... .

Here one must disagree with Wilde also, for the lack of symmetry between the two sides of the mouth is clearly caused by the fact that the lower jaw had slipped to the left-hand side when the mould was taken. Wilde also thought that, 'the left eye was much less full and prominent than the right: in fact', he says, 'it is comparatively sunken and collapsed within the orbit'. He related this to the attack of orbital cellulitis from which Swift was said to have suffered some years previously (Wilson, 1958). Wilde was usually a meticulously accurate observer, but once more we must contradict him, for the simple reason that this alleged sinking and collapse of the eye does not exist, as anyone can see from looking at the cast.

\section{The Second Trinity Death-Mask}

I have expressed these opinions some years ago (Wilson, I95I), and recently have been able to confirm them by the acquisition of what $I$ believe to be a hitherto undescribed death-mask of the Dean (Fig. 2.). This mask is of extreme interest because it was taken before the post-mortem. I acquired it from the executors of the late Mr. Frank Crawley, F.R.C.S.I., who had inherited it from his father, Mr. Chetwode Crawley. He had in turn bought it from W. C. K. Wilde, Sir William's elder son, who had likewise inherited it from his father. These details are described in a piece of paper pasted into the hollow back of the mask, which reads as follows:

This mask of Dean Swift was purchased by me in $188_{5}$ from W. C. K. Wilde, who inherited it from his father, Sir William Wilde, the Dean's biographer.

W. Chetwode Crawley. 


\section{The Death-Masks of Dean Swift}

The face is dark brown in colour and has obviously been painted with some substance which has chipped away in places. This paint has been identified as balsam of copaiba, which when first applied would be flesh-coloured but would later turn dark brown.

The name DEL VEccHo is incised in bold roman letters on the back of the cast. It is presumably the signature of the craftsman who made it, but who he was I do not know. It is possible that he was an ancestor of the art dealer Del Vecchio at whose premises at 26 Westmoreland Street the Irish Society of Artists held their exhibitions in 1812 and 1813 .

The features of this cast (which I have called the second Trinity mask) correspond so closely with the other that there can be no doubt of its identity. Nor can there be any doubt that it is indeed a death-mask rather than, for instance, a cast taken from a marble bust. The differences in detail between the two masks are very interesting, and nearly all derive from the fact that the earlier mask was taken before the post-mortem, probably during the period of rigor mortis, before the acceleration of the morbid processes of death and bodily decay. In consequence the whole appearance of the face is firmer and stronger, and more in accordance with what one would expect Swift to look like, even in death. The nose is not quite so finely chiselled, the cheeks are not so puffy and swollen, and there are various other small differences of detail which might be explained by supposing that a day or so had elapsed between the taking of the two casts. The principal difference, however, is in the shape and expression of the mouth. When this mask was made the Dean's false teeth had not been removed, as they had been by the time the later cast was taken, and their presence helps to preserve the powerful semblance of his face. Here the mouth is strong and firm, and full; the face as a whole is longer because the calvarium and teeth are in their proper places; the lower jaw has not yet slipped aside, and there is no trace of facial paralysis. The flabby looseness and indrawing of the lips in the later cast are not yet present, and this, with the fullness of the corners of the mouth, make the features much more like those we see in Jervis's portrait and the other likenesses of the Dean. The eyes are closed. They are quite evidently equal in size, and the left is by no means 'shrunken and collapsed within the orbit', as Wilde thought it was in the later cast. The top of the skull has not yet been sawn across for the purpose of the autopsy, and in consequence the marked recession of the forehead, which would be almost pathological had it existed in life, is shown to be an artefact. The eyebrows are much less prominent in this cast, and in their outer portion they are almost devoid of hair. This may have resulted from a senile atrophic change, for we know that in his earlier days the Dean had a fine luxurious growth. Knowledge of this no doubt prompted the sculptor to fashion fuller eyebrows when he made the eyes open and added the back of the head to the later cast.

It is difficult to understand why the later Trinity cast was taken at all, and particularly why it was taken at such a late stage. It suggests that the people who took it may not have known of the existence of the other, or may not have had access to it. In the minutes of St. Patrick's Hospital for 15 July 1784 , it is 


\section{T. G. Wilson}

stated that there was then in the Hospital a bust of Swift 'formed from a plaister of Paris mask taken from the Founder's Countenance at the charge of the Rev. Dr. Lyon'. Might it be possible that a sculptor was responsible for the earlier death-mask, and Dr. Lyon for the second? This gentleman, who was the most active of the Guardians appointed to look after Swift in 1742, was present at the Board meeting to which I have referred. The Master of the Hospital was ordered to have a 'proper mahogany bracket' made for this bust, which was to be 'cleaned in the best manner' and it was to be cared for properly in future. The need for a 'mahogany bracket' suggests that this cast was a whole head, and not merely a cast of the face, which would be better placed in a frame.

In spite of the Master's instructions, this particular bust was not taken care of, for it is not in the Hospital today, nor was it there in 1847 , when Wilde remarked:

we regret there is neither picture, bust, arms, carving, name, nor any other memorial of the munificent and distinguished founder to be seen in any part of this extensive institution.

-an omission which has of course long been remedied.

The history of the second Trinity mask before 1872 is quite unknown. From the evidence of the inscription we know it was in Sir William Wilde's possession at the time of his death. How, or when, he acquired it, I do not know, any more than I know anything of its previous history.

As I have said, I believe this mask has not been previously recorded. Why Wilde himself did not do so is another mystery. It undoubtedly upsets most of the deductions he made from the later mask, as set out in The Closing Years of Dean Swift's Life, but this would not act as a deterrent to one of Wilde's known scientific integrity. It is more likely that he obtained it late in life, when the fire of his zeal was sinking, and that he himself died before he found time to describe it.

I have presented the mask to Trinity College where it will remain in the museum with the other Swift relics. I believe that it presents a much truer likeness of the Dean than any other portrait, sculpture, or mask in existence. Here, even in death, is the powerful face of a great genius; here are the strong once-mobile features of one who has suffered much for himself and for others; the face of a man of tremendous sensibility and intellect. To have this mask and to handle it for a period is to be reminded irresistibly of Tennyson's lines in In Memoriam:

\footnotetext{
As sometimes in a dead man's face

To those that watch it more and more

A likeness hardly seen before

Comes out-to someone of his race.
}

\section{The Princeton Mask}

Recently (1952) the photograph of a third death-mask of Swift appeared in the American illustrated magazine Life. The editors of this magazine did not grant permission to reproduce the photograph: however, Mr. Howard G. Rice, Jr., who is in charge of the rare books and special collections of Princeton 
University Library where the mask now lies was kind enough to send me the excellent photograph which is reproduced herewith (Fig. 3).

As I have described above, the first Trinity mask has been made into a full head by the arbitrary addition of plaster, and the eyes have been made to appear open like those of a portrait bust. In order to do this it would obviously be necessary to add fresh plaster of paris around the orbits before the eyes were carved in. From the photographs supplied by Mr. Rice it is clear that the Princeton mask is taken not from Swift's own features but from a mould made from an original mask which was taken from Swift's own features and has now been lost. After this original mask was taken, plaster of paris had been added around the eyes preparatory to fashioning open eyes but this had not yet been done, and before starting it another mould was made from which this mask was taken. The craftsman probably made this second mould so that he could make additional copies should the first attempt fail. He then proceeded to carve out the eyes and add the eyebrows, manufactured a head out of plaster of paris, and added the right ear to form the first Trinity mask as we know it. The Princeton mask therefore represents an earlier stage of the first Trinity mask. The fresher appearance of the Princeton mask in the photographs suggest that this copy may have been cast more recently than the Trinity mask: if so, where the mould was preserved in the meantime is a mystery.

The Princeton mask forms one of a collection of death-masks bequeathed to Princeton University by Mr. Laurence Hutton (1843-1904) who collected death-masks as a hobby. A series of his articles, first published in Harper's Magazine in 1893, was in 1894 issued in book-form under the title Portraits in Plaster. An account of his experiences in collecting the masks was compiled in the volume Talks in a Library with Laurence Hutton, recorded by Isabel Moore (1905). In this book we read (pp. 199-200):

Sir William Wilde, the father of Mr. Oscar Wilde, wrote a book once to prove that Jonathan Swift was sane and unusually sane to the end of his life. But Sir Walter Scott, Swift's biographer, thought otherwise. They both of them knew and examined and commented upon the deathmask, kept for many years in Trinity College, Dublin. They realized and acknowledged its authenticity. Dr. Wilde compared it with the cast and the drawings of Swift's skull, made when his body was exhumed in $183^{8}$, and he accepted it as Swift himself. . . . The original mask, according to Dr. Wilde, disappeared from Trinity College, Dublin, in 1845 or 1846, and ... a copy of it, identical with Dr. Wilde's engraving of it, came into my possession some four years later through a little dealer in plaster casts in London whom I never found at any hour of the day or evening in a condition of perfect sobriety. He could never explain how he became possessed of it and he did not even know whose mask it was. And so what Trinity College, Dublin, Ireland, has lost forever, the University of Princeton, New Jersey, America, now owns.

Swift and 'Stella' were buried side by side in the Cathedral at Dublin, and nearly a century after the Dean's death their coffins were opened by members of the British Association, then holding its annual meeting in the Irish capital. The skulls were examined and cast, and Dr. Wilde's book contains drawings of them both. Where the original casts of these skulls are now I have never been able to learn.

Hutton was 'enthusiastic about his collection, a good raconteur, and certainly did not deliberately misrepresent facts' (Rice, 1953). Nevertheless, his stories 


\section{T. G. Wilson}

will not always stand up to scrutiny, and, of course, additional information has now come to light which was not available to him when he wrote. Some statements in his account must be corrected. One is that the 'original mask' did not disappear from Trinity in 1845 or 1846 . Another is that, as we have seen, the mask in Trinity is not identical with the Princeton mask. Finally, the original casts of the skulls to which he refers are in the Anatomical Museum of Trinity College.

\section{REFERENCES}

Benkard, Ernest (1929), Undying Faces. The Hogarth Press, London.

Hutton, Laurence (1894), Portraits in Plaster. Harper and Brothers, New York.

Life, 1952, 23 December.

Moore, IsABet (1905), Talks in a Library with Laurence Hutton, Recorded by Isabel Moore. G. P. Putnam \& Sons, New York.

Rice, Howard G., Jnr. (1953), Personal Communication.

Widdess, J. D. H., ft alia (1948), The Legacy of Swift. The Sign of the Three Candles, Dublin. Wilde, W. R. (1849), The Closing Years of Dean Swift's Life; with an Appendix Containing Several of his Poems hitherto Unpublished and Some Remarks on Stella. Hodges and Smith, Dublin.

Wilson, T. G. (1939), 'Swift's Deafness and his Last Illness', Irish Fournal of Medical Science, VIth Series, pp. 243-56. Cahill \& Co., Dublin.

Wilson, T. G. (195I), 'A Hitherto Undescribed Death-Mask of Dean Swift', Fournal of Royal Society of Antiquaries of Ireland, Lxxxi, 107. Dublin.

Wirson, T. G. (1958), 'The Mental and Physical Health of Dean Swift', Medical History, In, 175. Farnham, Surrey.

\section{ACKNOWLEDGMENTS}

My thanks are due to the Provost of Trinity College, Dublin, for giving me free access to the casts in Trinity; and to Inspector Wall of the Garda Siochana for much extremely valuable assistance. Mr. Ian Mitchell, Inspector Wall and Mr. Willard Starkes took the photographs. Mr. Michael Bourke, Headmaster of the National College of Art, Dublin, has given me valuable information about the methods by which death-masks are made. 